\title{
1 Helminth parasites decrease survival probability in young red deer
}

3 Claudia I. Acerini*1, Sean Morris ${ }^{1}$, Alison Morris ${ }^{1}$, Fiona Kenyon ${ }^{2}$, David McBean ${ }^{2}$, Josephine M.

4 Pemberton ${ }^{1}$, Gregory F. Albery ${ }^{3,4}$

5

6 1: Institute of Evolutionary Biology, School of Biological Sciences, University of Edinburgh, 7 Edinburgh, UK, EH9 3FL

8 2: Moredun Research Institute, Pentlands Science Park, Bush Loan, Midlothian, UK, EH26 0PZ

9 3: Wissenschaftskolleg zu Berlin, Berlin, Germany, 14193

10 4: Department of Biology, Georgetown University, Washington, DC, USA, 20007

11 *acerinic@gmail.com 


\section{Abstract}

14 Helminths are common parasites of wild ungulates that can have substantial costs for growth, 15 mortality, and reproduction. While these costs are relatively well documented for mature animals,

16 knowledge of helminths' impacts on juveniles is more limited. Identifying these effects is important

17 because young individuals are often heavily infected, and juvenile mortality is an important process

18 regulating wild populations. Here, we investigated associations between helminth infection and 19 overwinter survival in juvenile wild red deer (Cervus elaphus) on the Isle of Rum, Scotland. We 20 collected faecal samples non-invasively from known individuals and used them to count propagules

21 of three helminth taxa (strongyle nematodes, Fasciola hepatica, and Elaphostrongylus cervi). Using 22 generalised linear models, we investigated associations between parasite counts and overwinter 23 survival for calves and yearlings. Strongyles were associated with reduced survival in both age class, 24 and $F$. hepatica was associated with reduced survival in yearlings, while E. cervi infection showed no association with survival in either age class. This study provides observational evidence for fitness costs of helminth infection in juveniles of a wild mammal, and suggests that these parasites could play a role in regulating population dynamics.

29 Key words: Disease ecology, Helminths, wild mammal, survival, ungulate, fitness costs 


\section{Introduction}

31 Parasites are ubiquitous in natural populations and are often costly to the hosts they infect (Hudson et al., 2002). Whilst the consequences of parasitism in mammals are well documented for domestic livestock, evidence of their effects in wild populations is far more limited due to the practical difficulties of collecting long-term parasitological data from wild hosts - particularly large, longlived mammals (Coulson et al., 2018; Wilson et al., 2003). Wild mammals are typically infected with gastrointestinal helminth parasites, a paraphyletic clade of macro-parasitic worms, including tapeworms (Cestoda), roundworms (Nematoda), and flukes (Trematoda) (Taylor et al., 2015b). These parasites display a variety of life histories and induced pathologies in their hosts (McSorley and Maizels, 2012). Most frequently, helminths invade their host via the gastrointestinal tract, after freeliving larval stages are consumed by the host (Taylor et al., 2015b). Adult helminths live, feed, and reproduce within their hosts and their propagules are excreted into the environment with the faeces, from which they spread to other hosts either directly or indirectly, via an intermediate host (Taylor et al., 2015b). Quantification of infection is possible by counting these propagules within a host's faeces in a method known as faecal egg counts (FECs) (Taylor et al., 2015a). This non-invasive measure can be used as a proxy for an individual's parasite burden, defined as the actual quantity of adult helminths within the host (Budischak et al., 2015). Parasite count often varies with both extrinsic and intrinsic host factors. Age-dependent parasitism is common; juveniles are often the most heavily parasitised members in a population, predominantly attributed to their naïve immune systems and prioritisation of resources for growth rather than immunity (Ashby and Bruns, 2018; Wilson et al., 2003). Juveniles are a key demographic group and any parasite-mediated effects on their survival could play a role in population regulation (Gaillard et al., 2000).

The European red deer (Cervus elaphus) is a large ungulate that has great ecological importance as a wide-ranging herbivore and source of livestock diseases (Böhm et al., 2007; Fuller and Gill, 2001). 
Red deer are abundant in Scotland and culling regimes for population regulation have provided the basis for many parasitological investigations. These studies have documented the prevalence of endoparasites in Scottish red deer, including multiple species of strongyle nematodes (a family of worms whose eggs are indistinguishable by microscopy and so grouped together in assays), lungworms (Dictyocaulus spp.), the tissue nematode (Elaphostrongylus cervi), Sarcocystis spp., and the common liver fluke (Fasciola hepatica) (Böhm et al, 2006; Irvine et al., 2006; French et al., 2016). The study population of wild red deer on the Isle of Rum provide an excellent system for investigating the fitness consequences of parasitism. Longitudinal individual-based monitoring enables collection of complete life history information, and parasite data from non-invasive faecal sampling (Albery et al., 2021). The population hosts a variety of helminth parasites, the most prevalent taxa being strongyle nematodes, F. hepatica and E. cervi (Albery et al., 2018). Juvenile deer tend to be more heavily parasitised than adults, with calves ( $\leq 12$ months old) showing the highest strongyle intensities and yearlings (13-24 months old) showing the highest $F$. hepatica and E. cervi intensities (Albery et al., 2018). Mortality rates are high among juveniles, with many of these deaths occurring over the winter months (January-March), when environmental conditions are harshest and food is limited (Clutton-Brock et al., 1987; Coulson et al., 1997). Juvenile overwinter survival may be influenced by the extent of parasite infection. In other wild ungulates, helminth infection in juveniles has been shown to cause mortality over winter periods, exacerbating the effects of food shortage (Coltman et al., 1999). Strongyle infection negatively impacts future reproductive success and survival in adult female deer in the Rum study population (Albery et al., 2021), but to date there have been no investigations into the fitness costs of juvenile parasitism in this population.

Here, we investigate associations between survival probability of juvenile red deer on the Isle of Rum, and infection of strongyle nematodes, F. hepatica and E. cervi, quantified from faecal samples collected at three times of year. We predict that increases in helminth parasite burden in young red deer will decrease their subsequent overwinter survival probability. 


\section{Methods}

\subsection{Data collection}

This study uses data collected between 2016 and 2020 from a wild population of red deer situated on the North block of the Isle of Rum, Scotland. A detailed description of the study system and field data collection can be found in Clutton-Brock et al. (1982). After many years of study, the deer are relatively habituated to human presence. The 'deer year' begins on May $1^{\text {st }}$, marking the start of the calving season (May-July). During this time pregnant female deer are monitored daily for when they give birth to a single calf. Within a few hours of birth, calves are caught, sex determines, weighed and marked with a combination of collars, tags, and ear punches, to allow individual identification throughout their lives. Regular censuses of the population allow accurate individual life history data to be collected.

Faecal samples were collected in spring (April), summer (August) and autumn (November). A detailed description of faecal sampling and parasitological methods can be found in Albery et al. (2018). Individually recognised deer were observed defaecating from a distance and the faeces were collected as quickly as possible without disturbing the deer. In each season as many different individuals as possible were sampled. Faecal samples were kept as anaerobic as possible in resealable plastic bags and refrigerated at $4^{\circ} \mathrm{C}$ to prevent the hatching or development of parasite propagules until parasitological analysis was performed (within 3 weeks of collection) (Albery et al., 2018).

From a faecal subsample, parasite propagule counts were conducted for strongyle nematodes, Fasciola hepatica and Elaphostrongylus cervi as detailed in Albery et al. (2018). Briefly, strongyle nematode FECs were conducted via a sedimentation-salt flotation method accurate to 1 egg per gram 
102 (EPG) (Kenyon et al., 2013; Albery et al., 2018); faecal samples were homogenised in water to 103 suspend eggs, the suspension was then filtered, centrifuged at $200 \times \mathrm{g}$ for 2 minutes, and the 104 supernatant was removed using a vacuum. Retentate was mixed with saturated salt solution and then 105 centrifuged again. The less dense strongyle eggs that floated to the surface were collected and counted 106 under 4X magnification. F. hepatica eggs were counted by a sedimentation method (Taylor et al., 107 2015a); faecal matter was homogenised with water and filtered. The sample was then left to sediment; 108 the dense eggs that sank to the bottom were separated from the lighter material above and stained 109 with methylene blue to facilitate counting under 4X magnification. E. cervi larvae were counted by a 110 baermannization method (Gajadhar et al., 1994); faecal matter was wrapped in muslin cloth, 111 submerged in a tube of water and left for 20-24 hours for the larvae to emerge and fall to the bottom 112 of the tube. The supernatant was then removed, and the remaining larvae counted under $40 \mathrm{X}$ 113 magnification. Propagule counts were divided by the mass of the faecal subsample used, to give a 114 measure of parasitic burden as eggs per gram of faecal matter for strongyles and $F$. hepatica (EPG) 115 or larvae per gram of faecal matter for E. cervi (LPG). Our analysis uses faecal propagules counts 116 included in Albery et al. (2018) collected in 2016, and additional samples collected in 2017, 2018 117 and 2019.

\section{$118 \quad 2.2$ Statistical analysis}

119 All statistical analysis was performed in R version 4.0.3 (RStudio Team, 2021). For calves and 120 yearlings, we calculated prevalence (\%) and mean FEC of strongyles, F. hepatica and E. cervi in the 121 spring (April), summer (August), and autumn (November). We do not investigate parasite counts for 122 yearlings sampled in the spring (April) as they have already survived over the winter period and so 123 are not informative for survival analysis. We used binomial generalised linear models (GLM) to 124 explore the association of parasitic burden with subsequent overwinter survival in calves and 125 yearlings. Parasite burden, determined by FECs, was $\log (\operatorname{count}+1)$ transformed in all cases, to 
approximate normality. To investigate the survival of a calf through their first winter, we conducted generalised linear models with a logit-link function, using faecal sample data from the summer (model A) and autumn (model B) before the calves' first winter. In both models we included a response variable of first winter survival (binary; survived (1) or died (0)) and explanatory variables of sex (categorical; female, male), sample deer year (categorical) and strongyle count per gram of

131 faeces (continuous). We included $F$. hepatica count per gram of faeces (continuous) as an explanatory 132 variable in model $\mathrm{B}$ but not model $\mathrm{A}$, as $F$. hepatica infection is prepatent and FECs are not 133 meaningful when sampled from calves in the summer at the age of two to three months. We did not 134 fit E. cervi count in either model as infection is prepatent and FECs are not meaningful when sampled 135 from calves aged up to six months in the summer and autumn (Albery et al., 2018; Gajadhar et al., 136 1994). To investigate yearlings' survival through their second winter, we conducted generalised linear 137 models with a logit-link function, using faecal sample data from the spring (as calves; model C), 138 summer (as yearlings; model D) and autumn (as yearlings; model E) before the individuals' second 139 winter. In all three models we included a response variable of second winter survival (binary; survived 140 (1) or died (0)) and explanatory variables of sex (categorical; female, male), deer year (categorical), 141 strongyle count per gram of faeces (continuous), F. hepatica count per gram of faeces (continuous) 142 and E. cervi count per gram of faeces (continuous). Survival was $97.1 \%$ for calves and $98.1 \%$ for 143 yearlings in deer year 2019, preventing us from fitting a survival model to this year. For this reason, 144 before running the models, we removed samples corresponding to calf and yearling overwinter 145 survival in the deer year 2019; samples taken in the summer and autumn of the same deer year 146 (August and November 2019) and samples taken in spring of the previous deer year (2018; April 147 2019). 


\section{Results}

149 Strongyle prevalence and mean intensities were higher in calves than yearlings, peaking in calves 150 sampled in the spring aged ten to eleven months. Strongyle prevalence and intensity was lowest in

151 the autumn. F. hepatica prevalence and intensity peaked in spring and dropped in the summer and 152 autumn. E. cervi showed the highest mean intensity across all parasite taxa, with calves sampled in 153 the spring displaying the highest mean counts. Prevalence of E. cervi was highest in yearlings 154 sampled in the autumn (Table 1).

156 Table 1. Prevalence (\%) and mean faecal propagule counts of strongyles, $F$. hepatica (in eggs per 157 gram of faeces) and E. cervi (in larvae per gram of faeces) in calves and yearling red deer sampled in 158 the spring, summer, and autumn across all years (2016-2019). ' $\mathrm{P}$ ' indicates parasite is prepatent in 159 the sample and so prevalence and mean propagule counts are not meaningful.

\begin{tabular}{|c|c|c|c|c|c|c|c|}
\hline \multirow[b]{2}{*}{ Sample } & & \multicolumn{2}{|c|}{ Strongyles } & \multicolumn{2}{|c|}{ F. hepatica } & \multicolumn{2}{|c|}{ E. cervi } \\
\hline & ple & $\begin{array}{c}\text { Prevalence } \\
(\%)\end{array}$ & $\begin{array}{c}\text { Mean count } \\
\text { [range] } \\
(\mathrm{EPG})\end{array}$ & $\begin{array}{c}\text { Prevalence } \\
(\%)\end{array}$ & $\begin{array}{c}\text { Mean count } \\
\text { [range] } \\
(\mathrm{EPG})\end{array}$ & $\begin{array}{c}\text { Prevalence } \\
(\%)\end{array}$ & $\begin{array}{c}\text { Mean count } \\
\text { [range] } \\
\text { (LPG) }\end{array}$ \\
\hline \multirow{2}{*}{ Summer } & $\begin{array}{c}\text { Calves } \\
(\mathrm{N}=141)\end{array}$ & 87.2 & $\begin{array}{c}31.1 \\
{[0-194.0]}\end{array}$ & $\mathrm{P}$ & $\mathrm{P}$ & $\mathrm{P}$ & $\mathrm{P}$ \\
\hline & $\begin{array}{l}\text { Yearlings } \\
(\mathrm{N}=91)\end{array}$ & 89.0 & $\begin{array}{c}14.8 \\
{[0-169.0]}\end{array}$ & 83.5 & $\begin{array}{c}11.5 \\
{[0-46.7]}\end{array}$ & 85.7 & $\begin{array}{c}40.5 \\
{[0-249.2]}\end{array}$ \\
\hline \multirow{2}{*}{ Autumn } & $\begin{array}{c}\text { Calves } \\
(\mathrm{N}=159)\end{array}$ & 47.2 & $\begin{array}{c}3.91 \\
{[0-33.0]}\end{array}$ & 81.1 & $\begin{array}{c}8.86 \\
{[0-114]}\end{array}$ & $\mathrm{P}$ & $\mathrm{P}$ \\
\hline & $\begin{array}{l}\text { Yearlings } \\
(\mathrm{N}=91)\end{array}$ & 42.9 & $\begin{array}{c}3.40 \\
{[0-45.0]}\end{array}$ & 83.5 & $\begin{array}{c}11.3 \\
{[0-104.5]}\end{array}$ & 49.3 & $\begin{array}{c}49.3 \\
{[0-371.2]}\end{array}$ \\
\hline Spring & $\begin{array}{l}\text { Calves } \\
(\mathrm{N}=90)\end{array}$ & 95.5 & $\begin{array}{c}70.3 \\
{[0-468.0]}\end{array}$ & 90 & $\begin{array}{c}26.3 \\
{[0-132.0]}\end{array}$ & 91.9 & $\begin{array}{c}91.9 \\
{[0-817.4]}\end{array}$ \\
\hline
\end{tabular}

160 
161 A full listing of model effect sizes is displayed in Table 2. Below we provide mean parasite effect

162 sizes for each survival model, on the logistic-link scale as $\log ($ parasite count +1$)$. Overall, $63.1 \%$ of 163 calves survived through their first winter and $84 \%$ of yearlings survived through their second winter 164 (excluding data corresponding to overwinter survival in deer year 2019, which was not used in 165 survival analysis). Calf and yearling survival models consistently revealed a significant negative 166 association between faecal strongyle count and subsequent winter survival in each sampled season. 167 A calf's summer strongyle FEC was negatively associated with their first winter survival (model A, $168-0.513 \pm 0.193, \mathrm{p}=0.008)$. Calves that had the lowest summer strongyle FECs $(0 \mathrm{EPG}, 4.6 \%$ of 169 samples) had a $90.0 \%$ probability of surviving their first winter, whilst calves with the highest 170 summer strongyle FECs ( $>40$ EPG, $32.1 \%$ of samples) had a $<57.3 \%$ probability of survival (Figure 171 1A). A calf's autumn strongyle FEC was negatively associated with their first winter survival (model $172 \mathrm{~B},-0.858 \pm 0.300, \mathrm{p}=0.004)$. Calves that had the lowest autumn strongyle FECs $(0 \mathrm{EPG}, 56.9 \%$ of 173 samples) had an $81.3 \%$ probability of survival, whilst calves with the highest autumn strongyle FECs 174 (>10 EPG, 17.9\% of samples) had a $<35.7 \%$ probability of survival (Figure 1B).
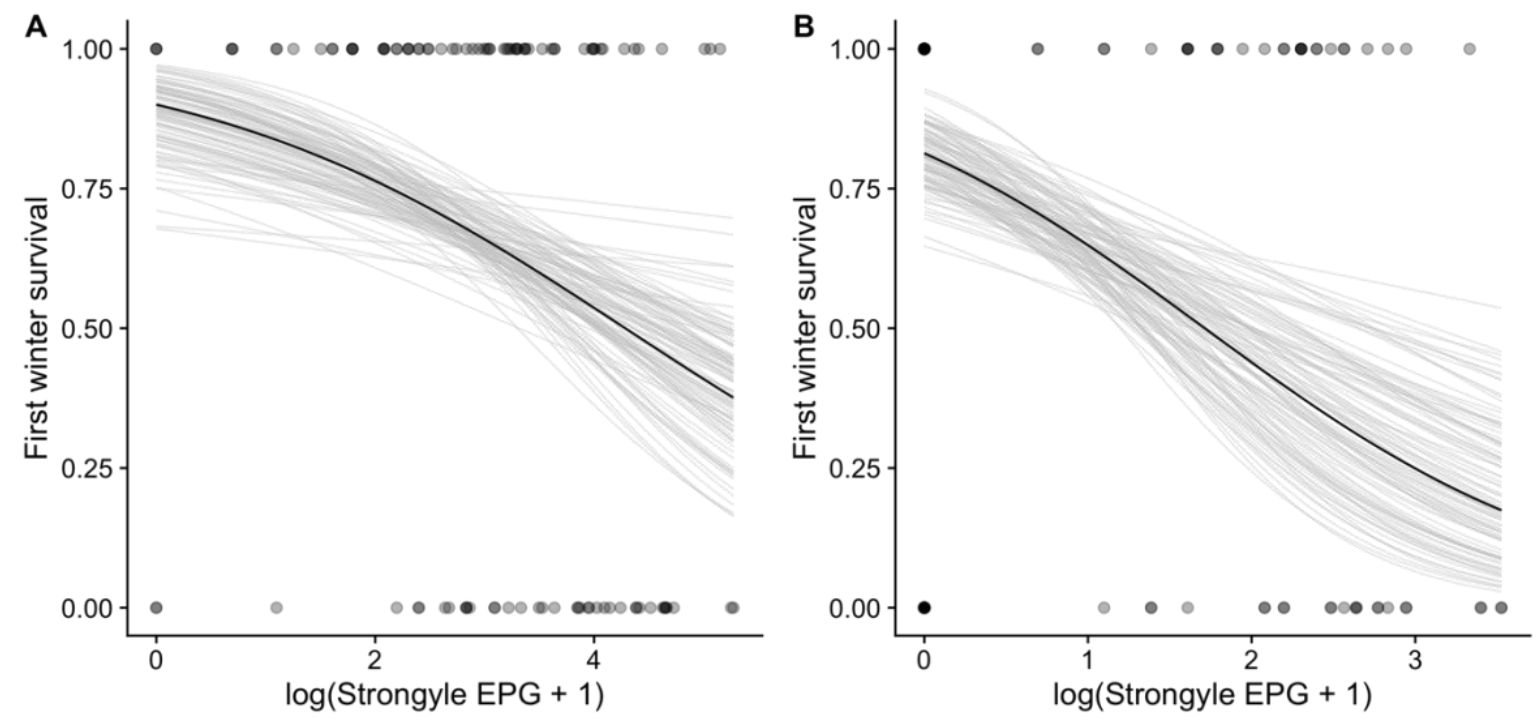
177 Figure 1: Probability of calf survival over their first winter $(1=$ survived, $0=$ died $)$ as predicted by their 178 strongyle FEC $(\log (\mathrm{EPG}+1))$ from samples taken in the $(\mathrm{A})$ summer (model $\mathrm{A})$ and $(\mathrm{B})$ autumn 179 (model B). Solid black line $=$ fitted logistic regression slope. Transparent grey lines $=100$ random 180 draws from model estimates to display variation in the estimated slope. Transparent grey dots $=$ 181 individual sample.

An individual's spring strongyle FEC was significantly negatively associated with survival over their second winter as yearlings (model $\mathrm{C} ;-0.869 \pm 0.372, \mathrm{p}=0.019$ ). Individuals with the lowest spring strongyle FECs ( $<10$ EPG, $13.4 \%$ of samples) had a $>95.4 \%$ probability of survival over their second winter as a yearling, and those with the highest spring strongyle FECs ( $>90$ EPG, $26.9 \%$ of samples) had a $<76.8 \%$ probability of survival (Figure 2A). A yearling's summer strongyle FEC was also significantly negatively associated with their overwinter survival (model $D ;-1.44 \pm 0.565, \mathrm{p}=0.011$ ). Yearlings with the lowest summer strongyle FECs ( $<5$ EPG, 10.9\% of samples) had a $>96.2 \%$ probability of survival over their second winter, whilst those with the highest summer strongyle FECs ( $>30$ EPG, $18.75 \%$ of samples) had a $<70.6 \%$ probability of survival (Figure $2 \mathrm{~B}$ ). A yearling's autumn strongyle FEC was significantly negatively associated with survival over their second winter (model E; $-1.88 \pm 0.698, \mathrm{p}=0.007)$. Yearlings with the lowest autumn strongyle FECs (0 EPG, 53.8\% of samples) had a $97.1 \%$ probability of overwinter survival, whilst those with the highest autumn strongyle FECs (10 EPG, $12.3 \%$ of samples) had a $<26.7 \%$ probability of survival (Figure $2 \mathrm{C}$ ). A deer's F. hepatica FEC was negatively associated with subsequent overwinter survival only in yearling summer samples (model $\mathrm{D} ;-0.839 \pm 0.365, \mathrm{p}=0.022$ ). Yearlings with the lowest summer $F$. hepatica FECs (0 EPG, 18.8\% of samples) had a 97.4\% probability of survival over their second 199 winter, whilst those with the highest summer $F$. hepatica FECs ( $>30$ EPG, 18.8\% of samples) had a $200<67.5 \%$ probability of survival (Figure 2D). A deer's E. cervi FEC was not significantly associated 
201 with subsequent overwinter survival in any sampled season (Table 2). In this sample of deer there 202 was also no significant difference in calf or yearling overwinter survival between males and females 203 (Table 2). Calf and yearling overwinter survival varied between years in models using data sampled 204 from autumn, with lower survival probabilities in 2016 compared to 2017 and 2018 (model B and model E, Table 2).
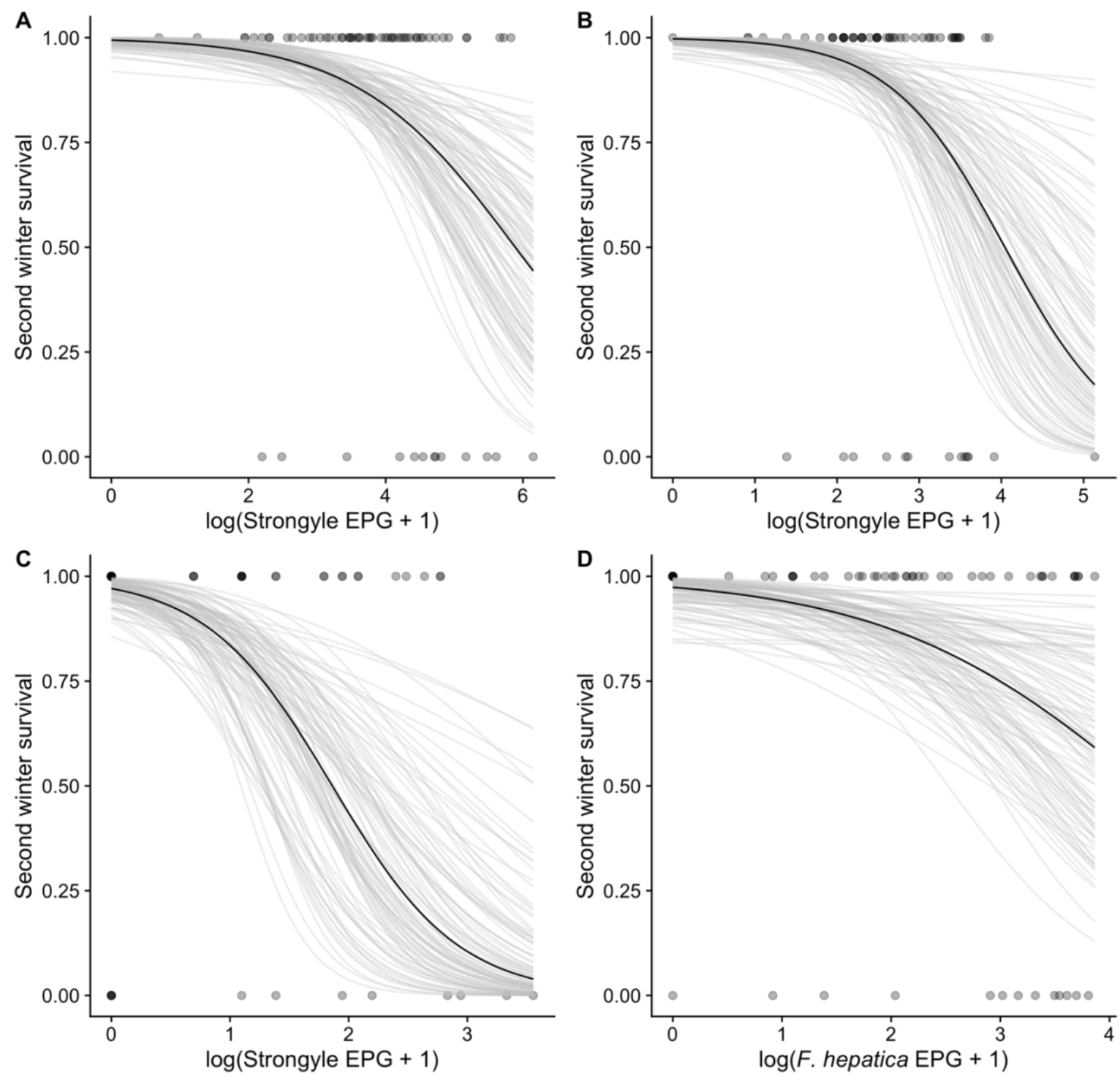

207 Figure 2: Probability of yearling survival over their second winter ( $1=$ survived, $0=$ died $)$ as predicted 208 by their strongyle FEC $(\log (E P G+1))$ from samples taken in the (A) spring as calves (model C), (B) 209 summer as yearlings (model D) and (C) autumn as yearlings (model E). And as predicted by (D) $F$. 
210 hepatica FEC $(\log (\mathrm{EPG}+1))$ from samples taken in the summer as yearlings (model $\mathrm{D})$. Solid black

211 line $=$ fitted logistic regression slope. Transparent grey lines $=100$ random draws from model

212 estimates to display variation in the slope. Transparent grey dots $=$ individual samples.

213

214 Table 2. Results from binomial generalised linear models predicting calf and yearling overwinter

215 survival using parasite FEC data collected in different seasons prior to winter (as described in table

216 subheadings). Estimates are given on the logistic scale. Negative estimates indicate a reduction in

217 survival probability. Significant effects are given in bold text.

\begin{tabular}{|c|c|c|c|c|}
\hline & Estimate & Std. Error & $Z$ value & $\operatorname{Pr}(>|\mathbf{z}|)$ \\
\hline \multicolumn{5}{|c|}{ Model A (Summer, calf survival, $n=109)$} \\
\hline (Intercept) & 2.316 & 0.790 & 2.931 & 0.003 \\
\hline Log(Strongyles EPG + 1) & -0.513 & 0.193 & -2.654 & 0.008 \\
\hline Sex [male] & -0.158 & 0.426 & -0.372 & 0.710 \\
\hline Deer year [2017] & -0.536 & 0.481 & -1.116 & 0.264 \\
\hline Deer year [2018] & 0.555 & 0.581 & 0.954 & 0.340 \\
\hline \multicolumn{5}{|c|}{ Model B (Autumn, calf survival, $n=123$ ) } \\
\hline (Intercept) & 0.729 & 0.549 & 1.328 & 0.184 \\
\hline Log(Strongyles EPG + 1) & -0.858 & 0.300 & -2.860 & 0.004 \\
\hline $\log (F$. Hepatica $\mathrm{EPG}+1)$ & -0.002 & 0.181 & -0.010 & 0.992 \\
\hline Sex [male] & -0.502 & 0.414 & -1.212 & 0.225 \\
\hline Deer year [2017] & 1.632 & 0.819 & 1.992 & 0.046 \\
\hline Deer year [2018] & 1.714 & 0.703 & 2.438 & 0.015 \\
\hline \multicolumn{5}{|c|}{ Model C (Spring, yearling survival, $n=67$ ) } \\
\hline (Intercept) & 3.451 & 2.153 & 1.603 & 0.109 \\
\hline Log(Strongyles EPG + 1) & -0.869 & 0.372 & -2.339 & 0.019 \\
\hline $\log ($ E. Cervi $\mathrm{LPG}+1)$ & 0.212 & 0.218 & 0.974 & 0.330 \\
\hline $\log (F$. Hepatica $\mathrm{EPG}+1)$ & -0.086 & 0.296 & -0.291 & 0.771 \\
\hline Sex [male] & 0.478 & 0.731 & 0.654 & 0.513 \\
\hline Deer year [2016] & 0.803 & 0.784 & 1.025 & 0.305 \\
\hline Deer year [2017] & 1.947 & 1.236 & 1.576 & 0.115 \\
\hline \multicolumn{5}{|c|}{ Model D (Summer, yearling survival, $n=64$ ) } \\
\hline (Intercept) & 5.964 & 2.277 & 2.620 & 0.009 \\
\hline Log(Strongyles EPG + 1) & -1.439 & 0.565 & -2.548 & 0.011 \\
\hline $\log ($ E. Cervi $\mathrm{LPG}+1)$ & 0.247 & 0.276 & 0.896 & 0.370 \\
\hline $\log (F$. Hepatica $\mathrm{EPG}+1)$ & -0.839 & 0.365 & -2.297 & 0.022 \\
\hline Sex [male] & 0.746 & 0.817 & 0.914 & 0.361 \\
\hline Deer year [2017] & 0.319 & 0.845 & 0.377 & 0.706 \\
\hline Deer year [2018] & 0.576 & 1.231 & 0.468 & 0.640 \\
\hline
\end{tabular}




$\begin{array}{lcccc}\text { (Intercept) } & 0.801 & 1.425 & 0.562 & 0.574 \\ \log (\text { Strongyles EPG + 1) } & -1.884 & 0.698 & -2.697 & \mathbf{0 . 0 0 7} \\ \log (\text { E. Cervi } \mathrm{LPG}+1) & -0.046 & 0.258 & -0.176 & 0.860 \\ \log (\text { F. Hepatica } \text { EPG }+1) & 0.451 & 0.333 & 1.353 & 0.176 \\ \text { Sex [male] } & -0.457 & 0.756 & -0.605 & 0.545 \\ \text { Deer year [2017] } & 3.564 & 1.662 & 2.145 & \mathbf{0 . 0 3 2} \\ \text { Deer year [2018] } & 3.394 & 1.999 & 1.698 & 0.090\end{array}$

\section{Discussion}

220 We provide observational evidence that parasite infection is associated with substantially reduced

221 survival probability in young red deer. Individuals with higher strongyle nematode intensities showed 222 a reduced overwinter survival probability, consistent with the observation that strongyle infection is negatively correlated with fitness in adult females (Albery et al., 2021). While our analysis cannot infer causality, adult strongyle nematodes are known to cause damage to their hosts' abomasal mucosa, and consequently cause disruption to nutrient absorption in ungulates (Hoberg et al., 2001). Indeed, studies experimentally removing helminths by administration of anthelminthic treatment have shown strongyle nematodes to cause mortality in other wild mammals e.g. Soay sheep (Ovis aries) (Coltman et al., 1999; Gulland, 1992), reindeer (Rangifer tarandus) (Albon et al, 2002), and snowshoe hares (Lepus americanus) (Murray et al., 1997). Taking this evidence together, it is therefore reasonable to consider that strongyle nematodes are having negative impacts on the health of juvenile red deer and are contributing towards overwinter mortality.

232 Studies of juvenile Soay sheep have uncovered a negative effect of strongyle nematodes on survival, 233 in addition to the effects of body weight, a correlate of body size (Sparks et al., 2020). A similar 234 effect may be occurring in red deer, but development of a non-invasive measure of body size for the 235 Rum study system would be necessary to disentangle size- and parasite-dependent effects on survival. 236 Nonetheless, our analysis shows a survival cost associated with strongyle infection in juvenile red 237 deer which may exert positive selection on resistance to infection, as has been observed in other ungulate study systems (Hayward et al., 2011). Furthermore, this negative association is observed 
despite low mean strongyle egg counts in both calves and yearlings compared to the mean strongyle counts that are observed in lamb and yearling Soay sheep (Craig et al., 2008). Strongyle egg counts peaked in calves sampled in spring (April), which may reflect a transmission strategy of coinciding maximum propagule output with the influx of immunologically naïve calves in May. The low intensities and prevalence of strongyle eggs in the autumn is likely due to a reduction in propagule output, as colder temperatures decrease transmission, rather than reductions in actual burden (Albery et al., 2018). In general, calves had higher strongyle intensities than yearlings, agreeing with previous findings, which may result from the negative effects of strongyle infection on juvenile overwinter survival and/or the maturation of the naïve immune system (Albery et al., 2018).

In the case of $F$. hepatica, yearling overwinter survival was predicted by the individual's count in summer, but not by its count in spring or autumn. This may be true seasonal variation, or a result of the selection of samples used in the yearling analysis (models C, D, and E). Only $\sim 16 \%$ of yearlings died in their second winter (in contrast to $\sim 37 \%$ of calves in their first year), which may have reduced the models' ability to reliably detect an association between $F$. hepatica FECs and survival. Ultimately, the analysis presented is restricted in estimating the association between $F$. hepatica and juvenile survival; collection of further $F$. hepatica FECs and fitness data from yearlings will be necessary to better understand their survival effects. $F$. hepatica is known to have a negative effect on weight gain in domestic cattle and sheep (Hayward et al., 2021). Similar effects of $F$. hepatica infection in wild red deer may explain their association with a reduced survival probability, as lighter individuals are less able to survive over winter periods of poor nutrition (Loison et al., 1999). nematodes infect the central nervous system and skeletal muscles of their hosts and propagated larvae migrate through the bloodstream to the lungs prior to being swallowed and excreted (Mason, 1989). 
263 Descriptions of the clinical symptoms of disease from E. cervi infection have included paresis of hind 264 limbs and pneumonia; however, pathogenicity is relatively low in red deer in Scotland (Mason, 1989). 265 Minimal pathology of E. cervi infection in juvenile red deer may explain its lack of association with subsequent overwinter survival probability. Furthermore, this result may reflect a host response of tolerance to E. cervi infection, where minimising the damage caused by infection is prioritised over eradicating the worms (McSorley and Maizels, 2012). This strategy could explain the high intensities and prevalence, and lack of age-bias of this parasite in the population (Albery et al., 2018). There was also no sex disparity in survival probability, contrary to expected male-biased mortality (Moore \& Wilson, 2002). However, this observation is not likely due to sex differences in parasite FECs, which were small in calves and yearlings for strongyles, and not observed for $F$. hepatica (Albery et al., 2018).

Host population density is predicted to positively affect helminth transmission (Tompkins et al., 2001); at higher population densities juveniles may show higher intensities of helminth infection, as has been observed in another wild ungulate population, Soay sheep (Hayward et al., 2014). Considering the survival costs of strongyle infection in juveniles demonstrated here, densitydependent parasitism could be involved in the density-dependent juvenile survival that occurs in the deer (Coulson et al., 1997). There is limited understanding of how parasites may regulate ungulate 280 hosts populations; however, experimental studies of wild reindeer suggest helminths may be capable 281 of regulating the population via density-dependent effects on host reproduction (Albon et al., 2002). Strongyle nematodes are likely to have mediating effects on population dynamics in red deer, by reducing juvenile survival and by reducing survival and future reproduction in adult females (Albery et al., 2021). Whilst the observational nature of the Rum red deer study system precludes the manipulation of helminth infection necessary to determine a regulatory role, collection of further years of parasite and fitness data paired with population density data would be valuable in developing 
years of longitudinal parasite and fitness data collection will inform the long-term effects of juvenile

289 parasitism on future fitness as deer are studied through to maturity and senescence.

\section{Acknowledgements}

291 Field data collection was supported by the UK Natural Environment Research Council (core grant 292 and PhD studentship to GFA). GFA is currently supported by a College for Life Sciences Fellowship 293 from the Wissenschaftskolleg zu Berlin. We are grateful to NatureScot for permission to work on 294 Rum.

\section{Competing Interest Statement}

296 The authors have declared no competing interest.

\section{References}

298 Albery, G. F., Kenyon, F., Morris, A., Morris, S., Nussey, D. H. \& Pemberton, J. M., 2018. 299 Seasonality of helminth infection in wild red deer varies between individuals and between parasite 300 taxa. Parasitology, 145, 1410-1420.

301 Albery, G. F., Morris, A., Morris, S., Kenyon, F., Nussey, D. H. \& Pemberton, J. M., 2021. Fitness costs of parasites explain multiple life-history trade-offs in a wild mammal. The American Naturalist, 197, 324-335.

304 Albon, S. D., Stien, A., Irvine, R. J., Langvatn, R., Ropstad, E. \& Halvorsen, O., 2002. The role of 305 parasites in the dynamics of a reindeer population. Proceedings of the Royal Society B: Biological 306 Sciences, 269, 1625-1632.

307 Ashby, B. \& Bruns, E., 2018. The evolution of juvenile susceptibility to infectious disease. 308 Proceedings of the Royal Society B: Biological Sciences, 285, 20180844. 
Böhm, M., White, P. C. L., Chambers, J., Smith, L. \& Hutchings, M. R., 2007. Wild deer as a source 310 of infection for livestock and humans in the UK. The Veterinary Journal, 174, 260-276.

311 Böhm, M., White, P. C. L., Daniels, M. J., Allcroft, D. J., Munro, R. \& Hutchings, M. R., 2006. The 312 health of wild red and sika deer in Scotland: An analysis of key endoparasites and recommendations 313 for monitoring disease. The Veterinary Journal, 171, 287-294

314 Budischak, S. A., Hoberg, E. P., Abrams, A., Jolles, A. E. \& Ezenwa, V. O., 2015. A combined 315 parasitological molecular approach for noninvasive characterization of parasitic nematode 316 communities in wild hosts. Molecular Ecology Resources, 15, 1112-1119.

317 Clutton-Brock, T. H., Albon, S. D. \& Guinness, F. E., 1982. Red deer: behavior and ecology of two 318 sexes University of Chicago Press, Chicago, IL.

319 Clutton-Brock, T. H., Major, M., Albon, S. D. \& Guinness, F. E., 1987. Early Development And 320 Population Dynamics In Red Deer .1. Density-Dependent Effects On Juvenile Survival. Journal Of 321 Animal Ecology. 56, 53-67.

322 Coltman, D. W., Pilkington, J. G., Smith, J. A. \& Pemberton, J. M., 1999. Parasite-mediated selection 323 against inbred soay sheep in a free-living island populaton. Evolution, 53, 1259-1267.

324 Coulson, G., Cripps, J. K., Garnick, S., Bristow, V. \& Beveridge, I., 2018. Parasite insight: assessing 325 fitness costs, infection risks and foraging benefits relating to gastrointestinal nematodes in wild 326 mammalian herbivores. Philosophical Transactions of the Royal Society B: Biological Sciences, 373, 32720170197.

328 Coulson, T., Albon, S., Guinness, F., Pemberton, J. \& Clutton-Brock, T., 1997. Population 329 substructure, local density, and calf winter survival in red deer (Cervus Elaphus). Ecology, 78, 852.

330 Craig, H., B., Tempest, J., L., Pilkington, G., J. \& Pemberton, M., J., 2008. Metazoan-protozoan 331 parasite co-infections and host body weight in St Kilda Soay sheep. Parasitology, 135, 433-441. 
332 French, A. S., Zadoks, R. N., Skuce, P. J., Mitchell, G., Gordon-Gibbs, D. K., Craine, A., Shaw, D., 333 Gibb, S. W. \& Taggart, M. A., 2016. Prevalence of Liver Fluke (Fasciola hepatica) in Wild Red Deer 334 (Cervus elaphus): Coproantigen ELISA Is a Practicable Alternative to Faecal Egg Counting for 335 Surveillance in Remote Populations. PLOS ONE, 11, e0162420.

336 Fuller, R. J. \& Gill, R. M. A., 2001. Ecological impacts of increasing numbers of deer in British 337 woodland. Forestry, 74, 193-199.

338 Gaillard, J. M., Festa-Bianchet, M., Yoccoz, N. G., Loison, A. \& Toïgo, C., 2000. Temporal variation 339 in fitness components and population dynamics of large herbivores. Annual Review of Ecology and $340 \quad$ Systematics, 31, 367-393.

341 Gajadhar, A. A., Tessaro, S. V. \& Yates, W. D., 1994. Diagnosis of Elaphostrongylus cervi infection 342 in New Zealand red deer (Cervus elaphus) quarantined in Canada, and experimental determination 343 of a new extended prepatent period. The Canadian veterinary journal 35, 433-437.

344 Gulland, F. M. D., 1992. The role of nematode parasites in Soay sheep (Ovis aries L.) mortality during 345 a population crash. Parasitology, 105, 493-503.

346 Hayward, A.D., Garnier, R., Watt, K.A., Pilkington, J.G., Grenfell, B.T., Matthews, J.B., Pemberton, 347 J.M., Nussey, H.H. and Graham, A.L., 2014. Heritable, heterogeneous, and costly resistance of sheep 348 against nematodes and potential feedbacks to epidemiological dynamics. American Naturalist, 184, $349 \quad$ S58-76

350 Hayward, A. D., Skuce, P. J. \& Mcneilly, T. N., 2021. The influence of liver fluke infection on 351 production in sheep and cattle: a meta-analysis. International Journal for Parasitology.

352 Hayward, A. D., Wilson, A. J., Pilkington, J. G., Clutton-Brock, T. H., Pemberton, J. M. \& Kruuk, 353 L. E., 2011. Natural selection on a measure of parasite resistance varies across ages and environmental 354 conditions in a wild mammal. Journal of Evolutionary Biology, 24, 16641676. 
Hoberg, E. P., Kocan, A. A. \& Rickard, L. G., 2001. Gastrointestinal strongyles in wild ruminants.

In: Samuel, W., Pybus, M. \& Kocan, A. A. (eds.) Diseases of wild mammals. Iowa State University Press, Iowa, 193-227.

Hudson, P., Rizzoli, A., Grenfell, B. T., Heesterbeek, H. \& Dobson, A. P., 2002. The ecology of wildlife diseases, Oxford University Press, Oxford, UK. $465-475$.

363 Kenyon, F., McBean, D., Greer, A,W, Burgess, C, G. S., Morrison A. A., Bartley, D.J., Bartley, Y,, 364 Devin, L., Nath, M. \& Jackson, F., 2013. A comparative study of the effects of four treatment regimes 365 on ivermectin efficacy, body weight and pasture contamination in lambs naturally infected with 366 gastrointestinal nematodes in Scotland. International Journal for Parasitology: Drugs and Drug 367 Resistance, 3, 77-84.

368 Loison, A., Langvatn, R. \& Solberg, E. J., 1999. Body mass and winter mortality in red deer calves: 369 disentangling sex and climate effects. Ecography, 22, 20-30.

370 Mason, P. C., 1989. Elaphostrongylus cervi - a review. Surveillance, 16, 3-10.

371 Mcsorley, H. J. \& Maizels, R. M., 2012. Helminth infections and host immune regulation. Clinical 372 Microbiology Reviews, 25, 585-608.

373 Moore, S. L. \& Wilson, K., 2002. Parasites as a Viability Cost of Sexual Selection in Natural 374 Populations of Mammals. Science, 297, 2015-2018.

375 Murray, D. L., Cary, J. R., \& Keith, L. B., 1997. Interactive Effects of Sublethal Nematodes and 376 Nutritional Status on Snowshoe Hare Vulnerability to Predation. Journal of Animal Ecology, 66(2), $250-264$. 
378 Rstudio Team., 2021. RStudio: integrated development environment for R. RStudio, PBC. RStudio, $379 \mathrm{PBCl}$

380 Sparks, A. M., Hayward, A. D., Watt, K., Pilkington, J. G., Pemberton, J. M., Johnston, S. E., 381 Mcneilly, T. N. \& Nussey, D. H., 2020. Maternally derived anti-helminth antibodies predict offspring 382 survival in a wild mammal. Proceedings of the Royal Society B, 287, 20201931.

383 Taylor, M., Coop, R. L. \& Wall, R., 2015a. Laboratory diagnosis of parasitism. Veterinary 384 Parasitology. John Wiley \& Sons, Inc, 259-312.

385 Taylor, M. A., Coop, R. L. \& Wall, R. L., 2015b. Veterinary helminthology. Veterinary Parasitology. 386 John Wiley \& Sons, Inc, 1-109.

387 Tompkins, D. M., Dobson, A. P., Arneberg, P., Begon, M. E., Cattadori, I. M., Greenman, J. V., 388 Heesterbeek, J. a. P., Hudson, P. J., Newborn, D., A., P., Rizzoli, A. P., Rosà, R., Rosso, F. \& Wilson, 389 K., 2001. Parasites and host population dynamics. In: Hudson, P. J., Rizzoli, A., Grenfell, B. T., 390 Heesterbeek, H. \& Dobson, A. P. (eds.) The Ecology of Wildlife Diseases. Oxford University Press, 391 Oxford, UK, 45-62.

392 Wilson, K., Grenfell, B. T., Pilkington, J. G., Boyd, H. E. G. \& Gulland, F. M. D., 2003. Parasites 393 and their impact. In: Pemberton, J. M. \& Clutton-Brock, T. H. (eds.) Soay Sheep: Dynamics and 394 Selection in an Island Population. Cambridge University Press, Cambridge, UK, 113-165. 